\title{
A controlled follow-up study of adolescents exposed to a school shooting - Psychological consequences after four months
}

\section{Suomalainen, L.}

$2011-11$

Suomalainen , L, Haravuori , H, Berg , N , Kiviruusu, O \& Marttunen , M 2011, ' A controlled follow-up study of adolescents exposed to a school shooting - Psychological consequences after four months ' , European Psychiatry , vol. 26 , no. 8 , pp. 490-497 . https://doi.org/10.1016/j.eurp

http://hdl.handle.net/10138/298579

https://doi.org/10.1016/j.eurpsy.2010.07.007

publishedVersion

Downloaded from Helda, University of Helsinki institutional repository.

This is an electronic reprint of the original article.

This reprint may differ from the original in pagination and typographic detail.

Please cite the original version. 


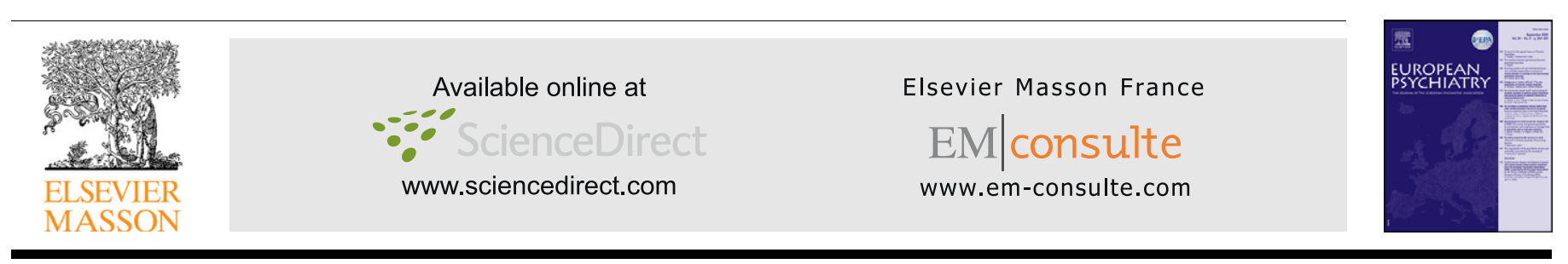

Original article

\title{
A controlled follow-up study of adolescents exposed to a school shooting - Psychological consequences after four months
}

\author{
L. Suomalainen $^{\text {a,*,b}}$, H. Haravuori ${ }^{\text {a,c }}$, N. Berg ${ }^{\text {a }}$, O. Kiviruusu ${ }^{\text {a }}$, M. Marttunen ${ }^{\text {a,b }}$ \\ ${ }^{a}$ Department of Mental Health and Substance Abuse Services, National Institute for Health and Welfare (MIPO/LAMI), PO Box 30, 00271 Helsinki, Finland \\ ${ }^{\mathrm{b}}$ Helsinki University and Department of Adolescent Psychiatry, Helsinki University Central Hospital, Helsinki, Finland \\ ${ }^{\mathrm{c}}$ Kellokoski Hospital, Hospital District of Helsinki and Uusimaa, Helsinki, Finland
}

\section{A R T I C L E IN F O}

\section{Article history:}

Received 26 February 2010

Received in revised form 1 July 2010

Accepted 16 July 2010

Available online 8 October 2010

\section{Keywords:}

Adolescents

School violence

Trauma

Posttraumatic stress disorder

PTSD

\begin{abstract}
A B S T R A C T
Background: In November 2007, a student shot eight people and himself at Jokela High School, Finland. This study aims to evaluate the long-term effects of exposure to a school shooting among adolescents. Method: Associations between psychological outcomes and background factors were analysed and compared with "comparison students" four months after the incident. A questionnaire including Impact of Event Scale (IES) and General Health Questionnaire (GHQ-36) was used.

Results: Half of the females and a third of the males suffered from posttraumatic distress. High level of posttraumatic distress (IES $\geq 35$ ), predicting PTSD, was observed in $27 \%$ of the females and $7 \%$ of the males. The odds ratio was 6.4 (95\% confidence interval 3.5-10.5) for having high levels of posttraumatic distress. Severe or extreme exposure and female gender were found to increase the risk. Forty-two percent of the females and $16 \%$ of the males had psychiatric disturbance (GHQ $\geq 9$ ). Severe or extreme exposure, older age and female gender increased the risk. Perceived support from family and friends was found to be protective.

Conclusions: The observed risk and protective factors were similar to earlier studies. Follow-up will be essential in identifying factors predicting persisting trauma-related symptoms in adolescence.
\end{abstract}

() 2010 Elsevier Masson SAS. All rights reserved.

\section{Introduction}

On November 7th 2007, a student shot eight people and himself in Jokela High School in Finland. The shooter had posted a video in YouTube beforehand, announcing the massacre. Several students were exposed to the shooting and perceived potential threat to life. The incident was an intentional violent act within a school and a small community that was thought to be safe. It received extensive media coverage and lead to a nationwide debate.

Traumatic events can be processed or experienced without significant distress or impairment in functioning. However, they may have long-term psychological effects by causing diverse anxiety and affective disorders and, more specifically, posttraumatic stress disorder (PTSD) [6]. Even though there have been over 70 school shootings since 1966, only few studies concerning psychological consequences exist. After a sniper attack at a school yard in the United States in 1984, 38\% of the studied 159 children had moderate or severe PTSD one month later [34]. Dose effect of exposure was observed. Seventy-seven percent of the children who were on the playground had moderate to severe PTSD compared to

\footnotetext{
* Corresponding author. Tel.: +358 20610 6000; fax: +358 206107191 .

E-mail address: laura.suomalainen@hus.fi (L. Suomalainen).
}

$67 \%$ of the children within school premises, $26 \%$ of the children having gone home, and $18 \%$ of the children on vacation. Three quarters of the highly exposed children continued to have PTSD after 14 months [29]. In 1988, 64 children and 64 of their parents were screened six to 14 months after a school shooting that killed one and wounded several children in an American elementary school. PTSD symptoms were observed in $19 \%$ of the adults and in $27 \%$ of the children. PTSD was associated with emotional states recalled from the shooting, rather than with the proximity of the shooting [37]. Among 293 female students of Virginia Tech, 30\% were in the clinical range of posttraumatic symptoms at two months and $24 \%$ at six months after the mass casualty shooting in 2007 [26]. Previous social support and distress predicted resource loss after the shooting in this study.

Adolescent survivors of natural and man-made disasters suffer from both short-term and long-term psychological consequences $[5,11,17,35,42,44]$. Especially the directly exposed show higher prevalence of symptoms [22]. In a youth café fire in Volendam, the Netherlands, 250 adolescents were wounded and 14 died. Exposed adolescents showed increased rates of anxiety, depression, thought problems, aggression and alcohol abuse after five months [35]. Among young student survivors of a shipping disaster, the sinking of "Jupiter" in Greek waters five to eight years previously, the prevalence of PTSD was 54\% [44]. Furthermore, 25\% of 
adolescent study participants met DSM-IV criteria for PTSD 18 months after a discotheque fire in Gothenburg, Sweden [7].

The prevalence of diagnosed PTSD in adolescents is approximately 30-40\% following various kinds of traumatic experiences [2]. In a meta-review of 36 studies summarizing data of 2697 children and adolescents exposed to traumatic events, the overall prevalence of PTSD was $37 \%$ with rates of $27 \%$ in adolescents and $39 \%$ in younger children [12]. In one epidemiological study of a community sample of older adolescents, $43 \%$ experienced at least one potentially traumatic event by the age of 18 years [15]. PTSD developed in $14.3 \%$ of these youths. In $37.5 \%$ of them PTSD symptoms lasted one to three years. Overall lifetime prevalence in the total sample was $6.3 \%$. In another study of a population of children and adolescents followed up until 16 years of age, $68.2 \%$ were exposed to traumatic events and $13.4 \%$ of them developed posttraumatic symptoms. However, overall lifetime prevalence of PTSD was as low as 0.5\% [8].

Although adolescents exhibit adult-like PTSD symptoms, subclinical symptoms affect well-being and may disturb the developmental tasks of adolescence, e.g. impede development of autonomy from parents or hinder forming a realistic view on world and the risks of life [2]. Adolescents with a lifetime diagnosis of PTSD have substantial and widespread impairment in functioning [15]. Even traumatized adolescents without PTSD diagnosis show deficits compared to those without experienced traumas [15]. Furthermore, exposure to traumatic events increases risk for substance abuse in adolescents and young adults $[3,6,10]$. Following traumatic experiences, females are more likely to show internalizing symptoms such as anxiety and depression, whereas males are more likely to show externalizing symptoms [9]. The studies have conflicting findings on gender differences in the risk for substance abuse. Traumatized adolescent girls have been found to have higher risk than boys for substance abuse but no difference is observed in young adults except in the case of sexual abuse [10].

Risk factors for developing PTSD tend to be cumulative. Evidence of psychopathology before trauma exposure, previous traumatisation, childhood adverse life events and disruption in social support network are strong predictors of trauma-related psychopathology. Other known risk factors for developing PTSD are female gender, family history of psychiatric disorders, life stress, low socioeconomic status and low educational level [8]. In general, PTSD symptoms are associated with the level of trauma exposure, perceived threat to life, severity and proximity to the traumatic event and emotions associated with trauma [27]. Perceived support from parents, classmates and teachers seem to associate with a lower risk of PTSD after stress. Studies including natural disasters, community violence, sexual and physical abuse, parental homicide and serious illness have documented the importance of parental support and parents' capability to cope with the trauma regardless of their own emotional reaction in preventing PTSD symptoms of children and adolescents [16,33].

The aim here was to investigate the incidence of posttraumatic distress, general psychiatric disturbance and possible changes in substance use four months after the incident among the students exposed to the school shooting in Jokela High School, Finland, November 2007. Associations between psychological outcomes and the level of the exposure and background factors, such as gender, social support and socioeconomic status of the family were analysed and compared with unexposed students from a comparison school.

We expected to find rates of posttraumatic stress in the adolescents recovering from the Jokela school shooting between $30-40 \%$, comparable to earlier studies. A higher rate of posttraumatic stress was expected in the severely exposed students, in those who had received mental support before the shooting or had impairments in social support network. Females were expected to have more symptoms than males.

\section{Subjects and methods}

\subsection{The incident}

The school shooting occurred at Jokela High School, a public secondary school (students aged 13-19), in November 2007. Jokela is an industrial urban area located $45 \mathrm{~km}$ from Helsinki, the capital of Finland. Jokela is part of the municipality of Tuusula and has 6000 inhabitants.

One of the school's students, an 18-year-old male, shot to death eight persons: five male students and one female student, the school principal and the school nurse. The shooter shot himself after the arrival of the police. One other person suffered gunshot wounds, and eleven people were injured by shattering glass while escaping from the school building. Several students saw the shooter moving inside the school and witnessed him shooting. Many students hid inside the school building up to hours until police released them after having secured the area. On the morning of the incident, the shooter posted a video on YouTube announcing the massacre at the school.

Psychosocial help for the community began rapidly. The crisis intervention was conducted by Vantaa Emergency Crisis Centre; physically the crisis work was conducted in a local church and a community centre. Crisis workers included Tuusula primary health care and social workers, psychologists trained in crisis work and volunteers (Finnish Red Cross), adolescent psychiatric outpatient unit workers and church employees. The students and teachers were prepared before returning to the school about one week after the incident. The crisis workers accompanied and supported them during the first days back in school.

Long-term psychosocial help for the students was organized within the school, providing school nurse, social worker and mental health professional services. Need for psychotherapeutic treatment has been evaluated by coordinating workers and treatment is mainly provided by private sector therapists. An adolescent psychiatric outpatient unit has also been utilized.

\subsection{Subjects}

All the students of the Jokela High School at the time of the incident, aged 13-19 years, were invited to participate in the study $(n=474)$ (Fig. 1). The data presented here were collected using a questionnaire administered in March 2008. Teachers, students and their parents were informed about the rationale, purpose and aims of the study beforehand. Participation was voluntary and each participant was asked to sign a written informed consent. Signed informed consent was required from parent or guardian of the students under 15 years according to Finnish legislation. Parents of minors were informed and they had the opportunity to deny participation. The study protocol was accepted by the Ethics Committee of Helsinki University Central Hospital.

\subsection{Collection of data}

The Ethics Committee required a procedure where consent had to be retrieved before the questionnaire could be administered. Two information events were arranged for the exposed students in February 2008. The information and approval forms were mailed with a return envelope to the students not present.

Students consenting to participate filled in questionnaires in classrooms at school in March 2008. The investigators and crisis workers were present at the time in case any questions arose or the students felt a need to talk afterwards. For the students under 


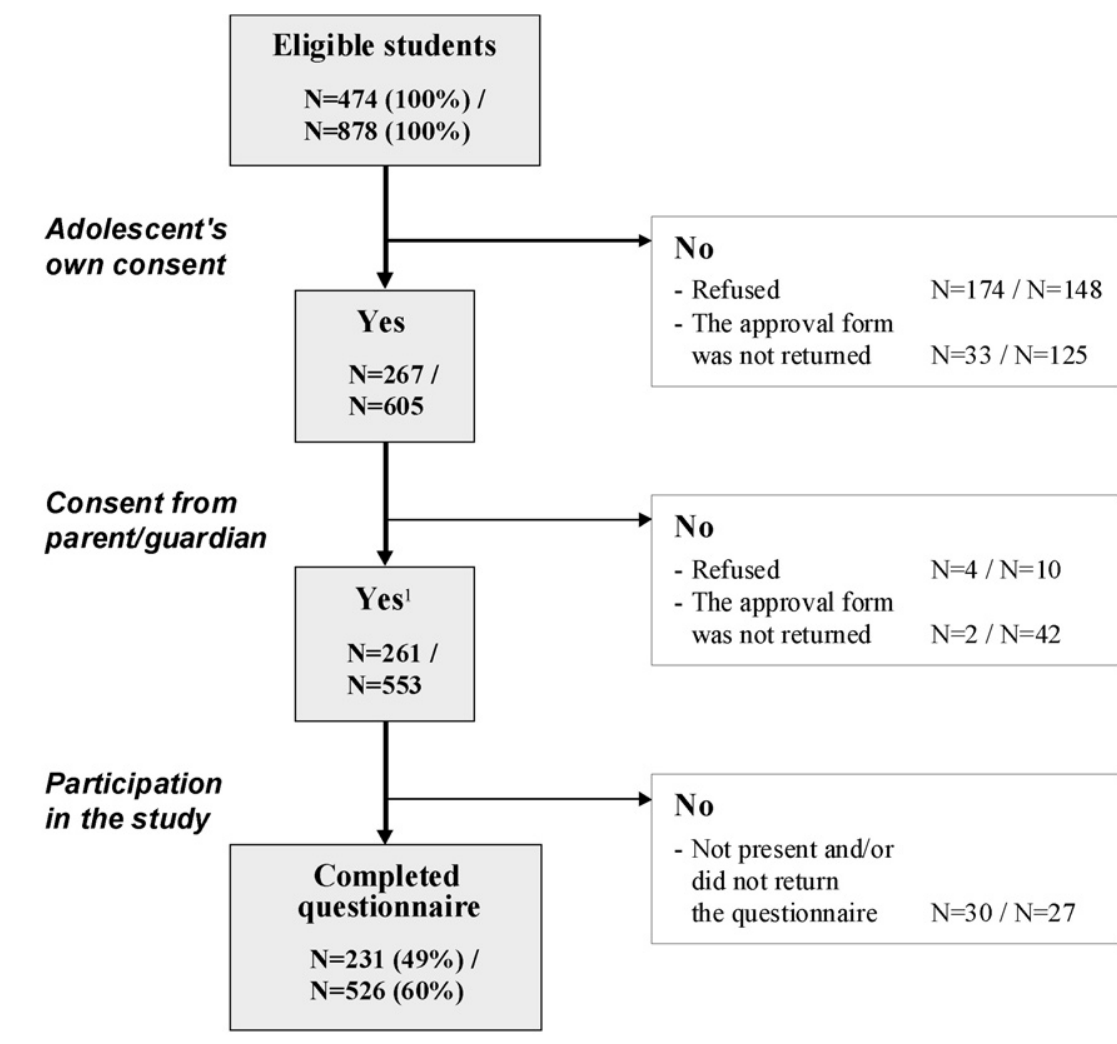

${ }^{1}$ Including 70 students in Jokela and 126 in Pirkkala High School with no returned approval form from parent/guardian allowed to participate because aged 15 years or older

Fig. 1. Recruitment process and participation in the study in Jokela High School (before slash) and Pirkkala High School (after slash).

15 years consenting to participate themselves, the questionnaire was given only after receiving an approval form from the parents. The questionnaires were mailed with a return envelope to the students who agreed to participate in the study but were absent from school at the time the questionnaires were filled in the classrooms. Reminder letters were sent twice (Fig. 1).

The comparison group was drawn from the students of Pirkkala High School, aged 13-19 $(n=878)$ (Fig. 1). The municipality of Pirkkala (population 15,000 inhabitants) is situated in the province of Western Finland near the city of Tampere, which is the third largest city in Finland. The information event was arranged in February 2008. The questionnaires were filled in March 2008. The procedure and collection of data were similar to Jokela. Reminder letters were sent twice, however, only to the students who were graduating from High School, since they were not present at school during the collection of the data.

\subsection{Response rates}

Approved consent was received from 55\% ( $n=261)$ of the Jokela High School students (Fig. 1). There were 231 (49\%) participants of whom $55 \%$ filled in the questionnaire at school and $45 \%$ returned it by mail. Thirty-eight percent $(n=178)$ of the students (or their parent/guardian) refused to participate in the study and $7 \%(n=35)$ did not return the approval form. Of the participants, $61 \%(n=141)$ were females and 39\% $(n=90)$ males. Non-participation was related to male sex (65\% among males vs. $35 \%$ among females, $P<0.001)$, but there were no differences in mean age between participants and non-participants (15.0 vs. $14.9, P=0.907)$.

In the comparison school, the approved consent was received from $63 \%(n=553)$ of the eligible students (Fig. 1$)$. There were 526
(60\%) students who completed the questionnaire, $85 \%$ at school, $15 \%$ returned it by mail. There were $158(18 \%)$ refusals and in $19 \%$ of the cases $(n=167)$ the approval form was not returned. Of the participants, $57 \%(n=299)$ were females and $43 \%(n=227)$ males. Non-participation was more common among males than females (53\% vs. $25 \%, P<0.001$ ), but non-participants and participants did not differ in age (14.7 vs. $14.7, P=0.933$ ).

\subsection{Questionnaire}

The questionnaire was partly based on questions used in previous studies among Finnish youth [1,14,24]. The first part of the questionnaire contained questions about family and living arrangements, parental occupation, friendship relations, academic performance, general health, mental health and possible previous psychiatric treatments. Parental occupation was used to specify socioeconomic status. The students were asked about their exposure to the shooting and about the immediate support and possible trauma-related psychosocial support or care they received. Possible substance use, frequency and changes in use in last six months were investigated using three questions created for the purpose of this study.

Social support was assessed using the family and friend subscales from Perceived Social Support Scale Revised (PSSS-R) [4]. Both subscales have four items rated on a five-point (1-5) Likert scale resulting in theoretical ranges of $4-20$. PSSS-R has formerly been used in studies with Finnish adult and adolescent subjects $[25,36,41]$. In this study, the internal consistency of the PSSS-R (Cronbach's $\alpha$ ) was 0.91 for family subscale among the exposed students and 0.90 among the comparison students, and 0.89 for friends subscale in both of the groups. 
The Impact of Event Scale (IES) was used to assess posttraumatic distress following critical events [21]. The inventory consists of 22 questions with four answer categories; $0=$ not at all, 1 = rarely, 3 = sometimes, 5 = often. Of the 22 questions, only the original 15 (intrusion and avoidance subscales) were used to calculate the sum scores, thus resulting in a theoretical range of 0 75 . The cut-off point for having posttraumatic distress was set at $19 / 20$ as this was originally proposed to be a threshold for the high level of clinical concern [20]. The cut-off point for "severe" posttraumatic stress was set at 34/35 which predicts clinical PTSD with 0.89 sensitivity and 0.88 specificity [30]. Both of these cut-off scores have been used in earlier studies but other cut-off scores have also been proposed $[23,31,38,43]$. The comparison group was instructed to use the most distressing event experienced during the past four months when answering IES to control for distress levels common for this age group. The questionnaire has been previously translated to Finnish and used in clinical practise by the Centre for Posttrauma Therapy and Trauma Education, Helsinki, Finland. In our study, internal consistency (Cronbach's $\alpha$ ) of the IES was 0.93 with both the exposed and the comparison students.

The General Health Questionnaire (GHQ) measures recent changes in a range of psychological and psychosocial symptoms [18]. The GHQ-36-questionnaire is based on the original 60-item edition of the GHQ [18]. When calculating the sum score, the 4point Likert scale items were first scored on a bimodal fashion (0-0$1-1)$, the theoretical range of the scale being $0-36$. GHQ-36 has been used previously with bimodality in Finnish adolescents [1]. The optimal cut-off point $8 / 9$ has sensitivity of 0.79 and specificity of 0.83 for detecting psychiatric disturbance in a Finnish sample [19]. Internal consistency (Cronbach's $\alpha$ ) of GHQ-36 was 0.95 among the exposed students and 0.94 among comparison students.

\subsection{Exposure to the school shooting}

The questionnaire included several detailed items about the exposure and there was also room for spontaneous report. For the purpose of this study, we created six categories for the severity of the trauma exposure based on the experienced threat to life and losses suffered. The categories were as follows: "No exposure": student of a comparison school who did not lose any acquaintances. "Mild exposure": student of Jokela High School who was not present at the time of the incident and did not lose any significant acquaintances (perished school principal and school nurse were taken into account if specified significant by the student). "Moderate exposure": was present at school at the time of the incident, but was not directly exposed to the shooting (no contact to the shooter, no hiding). Evacuated from the school building with or without guidance. Did not lose any significant acquaintance. "Significant exposure": had to act to escape the shooter or had to hide to avoid life danger or saw bodies or lost acquaintances. "Severe exposure": was near mortal danger or saw somebody threatened by gun or lost friend(s) or somebody significant. "Extreme exposure": was in mortal danger or saw somebody being shot and killed or lost a family member.

\subsection{Statistical analyses}

Differences between the groups were tested using analysis of variance and the $\mathrm{Chi}^{2}$ test. The effect of exposure and the background variables as potential risk or protective factors on psychological outcome were analysed using polynomial logistic regression (IES, three levels) and binomial logistic regression (GHQ). P-values $<0.05$ were considered statistically significant and for odds ratios (OR), 95\% confidence intervals (95\% CI) were calculated. All analyses were performed using SPSS 16.0 for Windows [40].

\section{Results}

\subsection{Background characteristics of participants}

Statistically significant differences existed between socioeconomic status (SES), age at the incident and social support from friends of the exposed and the comparison students and were controlled in further analyses. Most of the Jokela High School students were at least significantly exposed to the traumatic event since majority of the students lost someone (acquaintance, friend or family member) or became somehow threatened by the shooter (Table 1).

\subsection{Posttraumatic distress and psychiatric disturbance of exposed females and males compared to unexposed students}

Expectedly, posttraumatic distress was more common among students at Jokela High School than among comparison students. Mean and median IES scores calculated from the original 15 questions for the Jokela students and comparison students are presented in Table 2. Forty-three percent $(n=98)$ of the exposed had posttraumatic distress as measured by IES (IES 20-75). Females were more likely to report posttraumatic distress than males; $53 \%$ of the females and $28 \%$ of the males suffered from these symptoms (Table 3). Possible diagnosable PTSD (IES 35-75) was observed in $19 \%$ of the exposed, in $27 \%$ of the females and in $7 \%$ of the males. The odds ratio of those exposed to the shooting for posttraumatic distress was 3.8 and for probable PTSD 6.0 (Table 3). Both the exposed females and males suffered significantly more often from posttraumatic distress and probable PTSD compared to comparison students (Tables 2 and 3). Based on the GHQ-36 screening, $32 \%$ of the exposed, $42 \%$ of the females and $16 \%$ of the males, had psychiatric disturbance. Compared to the unexposed, the OR of the exposed was 4.0; the effect was significant and of about equal size among females and males (Table 3 ).

\subsection{Changes in substance use four months after the shooting}

While there was no difference between the exposed students and comparison students in the proportion of those reporting "no changes" in substance use during past six months $(81.1 \%$ vs. $81.4 \%$, $\chi^{2}=0.007, \mathrm{df}=1, P=0.931$ ), the proportion of those reporting "increase in substance use" during past six months was more common among the exposed than the unexposed (13.3 vs. $8.5 \%$, $\left.\chi^{2}=4.015, \mathrm{df}=1, P=0.045\right)$. Odds ratio of the exposed for substance use increase was 1.65 (95\% CI: 1.01-2.71). However, controlling for the differences in background variables turned this effect insignificant ( $\mathrm{OR}=1.51,95 \% \mathrm{CI}: 0.91-2.50)$. The age difference between the exposed and comparison students (the mean age of the exposed group being higher, Table 1) explained the difference of increased substance use.

\subsection{Risk factors for posttraumatic distress and probable PTSD}

According to previous literature, seven variables from background factors were selected as possible predictors of posttraumatic distress or probable PTSD (Table 4). Among exposed students, severe or extreme exposure against mild to significant exposure and female sex were found to significantly increase the risk for probable PTSD (IES 35-75). Perceived social support from family and friends decreased the risk for probable PTSD significantly (Table 4). The same predictors prevailed in the multivariate model, although their effects tended to become 
Table 1

Sociodemographic and clinical characteristics of the students exposed to the school shooting and comparison students.

\begin{tabular}{|c|c|c|c|c|c|}
\hline Characteristic & $\begin{array}{l}\text { Exposed } \\
(n=231)\end{array}$ & students & $\begin{array}{l}\text { Comparison } \\
(n=526)\end{array}$ & students & $P$ \\
\hline $\begin{array}{l}\operatorname{Sex}, \%(\mathrm{n}) \\
\text { Male } \\
\text { Female }\end{array}$ & $\begin{array}{l}39.0 \\
61.0\end{array}$ & $\begin{array}{l}(90) \\
(141)\end{array}$ & $\begin{array}{l}43.2 \\
56.8\end{array}$ & $\begin{array}{l}(227) \\
(299)\end{array}$ & 0.281 \\
\hline Age at the incident, years, mean (SD) & 15.0 & $(1.7)$ & 14.7 & $(1.5)$ & 0.017 \\
\hline $\begin{array}{l}\text { SES, \% (n) } \\
\text { Entrepreneur } \\
\text { Upper middle class } \\
\text { Lower middle class } \\
\text { Working class } \\
\text { Other }^{\mathrm{a}}\end{array}$ & $\begin{array}{r}9.8 \\
35.6 \\
36.6 \\
13.7 \\
4.4\end{array}$ & $\begin{array}{l}(20) \\
(73) \\
(75) \\
(28) \\
(9)\end{array}$ & $\begin{array}{r}13.0 \\
45.2 \\
25.7 \\
11.7 \\
4.5\end{array}$ & $\begin{array}{l}(61) \\
(213) \\
(121) \\
(55) \\
(21)\end{array}$ & 0.031 \\
\hline $\begin{array}{l}\text { Living arrangements, \% (n) } \\
\text { With both biological parents } \\
\text { With one biological parent } \\
\text { Other arrangements }{ }^{\mathrm{b}}\end{array}$ & $\begin{array}{r}73.9 \\
23.0 \\
3.0\end{array}$ & $\begin{array}{l}(170) \\
(53) \\
(7)\end{array}$ & $\begin{array}{r}76.6 \\
22.3 \\
1.1\end{array}$ & $\begin{array}{l}(402) \\
(117) \\
(6)\end{array}$ & 0.170 \\
\hline $\begin{array}{l}\text { Perceived social support, mean (SD) } \\
\text { Family } \\
\text { Friends }\end{array}$ & $\begin{array}{l}17.6 \\
17.8\end{array}$ & $\begin{array}{l}(2.9) \\
(2.6)\end{array}$ & $\begin{array}{l}17.4 \\
17.1\end{array}$ & $\begin{array}{l}(3.0) \\
(3.1)\end{array}$ & $\begin{array}{l}0.468 \\
\mathbf{0 . 0 0 3}\end{array}$ \\
\hline Previous mental support from adult (other than guardian), \% (n) & 10.8 & $(25)$ & 13.9 & $(73)$ & 0.242 \\
\hline $\begin{array}{l}\text { Level of exposure, } \mathrm{n}(\%) \\
\text { No exposure } \\
\text { Mild } \\
\text { Moderate } \\
\text { Significant } \\
\text { Severe } \\
\text { Extreme }\end{array}$ & $\begin{array}{r}0.0 \\
4.8 \\
0.9 \\
65.4 \\
22.1 \\
6.9\end{array}$ & $\begin{array}{l}(0) \\
(11) \\
(2) \\
(151) \\
(51) \\
(16)\end{array}$ & $\begin{array}{r}100.0 \\
0.0 \\
0.0 \\
0.0 \\
0.0 \\
0.0\end{array}$ & $\begin{array}{l}(526) \\
(0) \\
(0) \\
(0) \\
(0) \\
(0)\end{array}$ & \\
\hline
\end{tabular}

a Student, housewife or pensioner.

b Living alone, with significant other or with an adult other than guardian.

Table 2

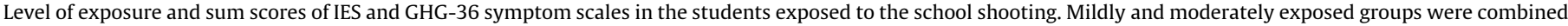
due to small number of students exposed moderately; comparison students are included as a no exposure group.

\begin{tabular}{|c|c|c|c|c|c|c|}
\hline \multirow[b]{2}{*}{ Level of exposure } & \multicolumn{3}{|l|}{ IES } & \multicolumn{3}{|c|}{ GHQ-36 } \\
\hline & Mean & (SD) & Median & Mean & (SD) & Median \\
\hline No exposure & 9.06 & $(12.12)$ & 4 & 2.95 & $(5.49)$ & 0 \\
\hline Mild to moderate & 9.15 & $(7.98)$ & 10 & 4.15 & $(4.56)$ & 2 \\
\hline Significant & 18.99 & $(16.48)$ & 13 & 6.27 & $(7.58)$ & 3 \\
\hline Severe & 23.96 & $(18.31)$ & 23 & 10.67 & $(9.37)$ & 8 \\
\hline Extreme & 28.53 & $(22.45)$ & 31 & 12.87 & (14.28) & 4 \\
\hline
\end{tabular}

stronger, already having significant effect on the level of posttraumatic distress (IES 20-34).

When differences in the predictors between the exposed and unexposed students were analysed using interaction terms, the only significant interaction term was found between gender and study group (exposed vs. unexposed) on posttraumatic distress
(IES 20-34) $(P=0.030)$, indicating that among the exposed students female sex was not a significant predictor of posttraumatic distress (IES 20-34) while among comparison student it was. However, female sex was a significant predictor of high level of posttraumatic distress (IES 35-75) among the exposed students and comparison students.

Table 3

Posttraumatic distress and psychiatric disturbance four months after the school shooting in exposed students and comparison students by sex.

\begin{tabular}{|c|c|c|c|c|c|c|c|c|c|c|c|c|c|c|c|}
\hline & \multicolumn{5}{|c|}{ Females } & \multicolumn{5}{|c|}{ Males } & \multicolumn{5}{|l|}{ Total } \\
\hline & \multicolumn{2}{|c|}{$\begin{array}{l}\text { Exposed } \\
(n=141)\end{array}$} & \multicolumn{2}{|c|}{$\begin{array}{l}\text { Comparison } \\
(n=299)\end{array}$} & \multirow[t]{2}{*}{$\mathrm{OR}^{\mathrm{a}}(95 \% \mathrm{CI})$} & \multicolumn{2}{|c|}{$\begin{array}{l}\text { Exposed } \\
(n=90)\end{array}$} & \multicolumn{2}{|c|}{$\begin{array}{l}\text { Comparison } \\
(n=227)\end{array}$} & \multirow[t]{2}{*}{$\mathrm{OR}^{\mathrm{a}}(95 \% \mathrm{CI})$} & \multicolumn{2}{|c|}{$\begin{array}{l}\text { Exposed } \\
(n=231)\end{array}$} & \multicolumn{2}{|c|}{$\begin{array}{l}\text { Comparison } \\
(n=526)\end{array}$} & \multirow[t]{2}{*}{$\mathrm{OR}^{\mathrm{a}}(95 \% \mathrm{CI})$} \\
\hline & $\%$ & $(n)$ & $\%$ & $(n)$ & & $\%$ & $(n)$ & $\%$ & $(n)$ & & $\%$ & $(n)$ & $\%$ & $(n)$ & \\
\hline \multicolumn{16}{|c|}{ Posttraumatic distress } \\
\hline IES 0-19 & 47.5 & $(66)$ & 75.3 & $(217)$ & & 72.2 & (65) & 95.0 & $(210)$ & & 57.2 & (131) & 83.9 & $(427)$ & \\
\hline IES 20-34 & 25.2 & (35) & 16.0 & $(46)$ & $3.5(2.0-6.1)$ & 21.1 & (19) & 3.6 & $(8)$ & $7.9(3.1-20.5)$ & 23.6 & $(54)$ & 10.6 & $(54)$ & $3.8(2.4-6.1)$ \\
\hline IES 35-75 & 27.3 & $(38)$ & 8.7 & $(25)$ & $7.1(3.7-13.5)$ & 6.7 & $(6)$ & 1.4 & (3) & $6.0(1.3-27.3)$ & 19.2 & $(44)$ & 5.5 & $(28)$ & $6.0(3.5-10.5)$ \\
\hline \multicolumn{16}{|c|}{ Psychiatric disturbance } \\
\hline $\mathrm{GHQ} \leq 8$ & 57.9 & $(81)$ & 82.2 & $(245)$ & & 84.4 & (76) & 96.0 & $(216)$ & & 68.3 & (157) & 88.1 & $(461)$ & \\
\hline $\mathrm{GHQ} \geq 9$ & 42.1 & (59) & 17.8 & $(53)$ & $4.7(2.8-7.8)$ & 15.6 & (14) & 4.0 & (9) & $4.4(1.7-11.3)$ & 31.7 & $(73)$ & 11.9 & $(62)$ & $4.0(2.6-6.1)$ \\
\hline
\end{tabular}

a Odds ratios of exposed (vs. controls) for having posttraumatic distress (polynomial logistic regression with IES score 0-19 as a reference category) or psychiatric

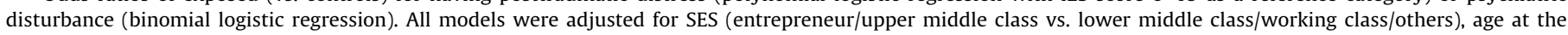
incident and perceived social support from friends. 
Table 4

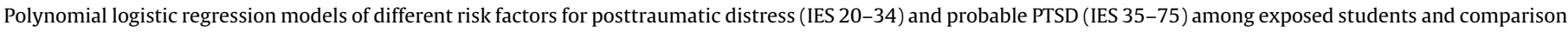
students.

\begin{tabular}{|c|c|c|c|c|c|c|c|c|}
\hline \multirow[b]{3}{*}{ Risk factor ${ }^{a}$} & \multicolumn{4}{|c|}{ Exposed students } & \multicolumn{4}{|c|}{ Comparison students } \\
\hline & \multicolumn{2}{|c|}{ IES $20-34^{c}$} & \multicolumn{2}{|c|}{ IES $35-75^{\mathrm{c}}$} & \multicolumn{2}{|c|}{ IES $20-34^{c}$} & \multicolumn{2}{|c|}{ IES $35-75^{c}$} \\
\hline & OR & $(95 \% \mathrm{CI})$ & OR & $(95 \% \mathrm{CI})$ & OR & $(95 \% \mathrm{CI})$ & OR & $(95 \% \mathrm{CI})$ \\
\hline \multicolumn{9}{|l|}{ Level of exposure } \\
\hline Mild to significant & 1.00 & & 1.00 & & - & & - & \\
\hline Severe or extreme & 1.68 & $(0.84-3.38)^{d}$ & 2.33 & $(1.13-4.82)^{d}$ & - & & - & \\
\hline \multicolumn{9}{|l|}{ Sex } \\
\hline Males & 1.00 & & 1.00 & & 1.00 & & 1.00 & \\
\hline Females & 1.81 & $(0.94-3.49)^{\mathrm{d}}$ & 6.24 & $(2.47-5.76)^{d}$ & 5.57 & $(2.57-2.07)^{d}$ & 8.07 & $(2.40-7.11)^{d}$ \\
\hline Age at the incident, years & 0.95 & $(0.78-1.15)$ & 1.05 & $(0.86-1.28)$ & 0.93 & $(0.76-1.13)$ & 0.92 & $(0.71-1.20)$ \\
\hline \multicolumn{9}{|l|}{ Socioeconomic status } \\
\hline Entrepreneur or upper middle class & 1.00 & & 1.00 & & 1.00 & & 1.00 & \\
\hline Lower middle class, working class or other ${ }^{\mathrm{b}}$ & 1.24 & $(0.63-2.42)$ & 1.00 & $(0.49-2.06)$ & 0.81 & $(0.44-1.49)$ & 1.39 & $(0.63-3.07)$ \\
\hline \multicolumn{9}{|l|}{ Living arrangements } \\
\hline With both biological parents & 1.00 & & 1.00 & & 1.00 & & 1.00 & \\
\hline With one biological parent or otherwise & 1.03 & $(0.50-2.13)$ & 1.23 & $(0.58-2.63)$ & 1.22 & $(0.64-2.34)$ & 1.94 & $(0.87-4.33)$ \\
\hline \multicolumn{9}{|l|}{ Perceived social support } \\
\hline Family & 0.90 & $(0.80-1.01)$ & 0.85 & $(0.76-0.96)^{d}$ & 0.90 & $(0.83-0.99)$ & 0.74 & $(0.66-0.82)^{d}$ \\
\hline Friends & 0.89 & $(0.79-1.01)^{\mathrm{d}}$ & 0.85 & $(0.75-0.97)^{d}$ & 0.98 & $(0.90-1.08)$ & 0.91 & $(0.82-1.02)$ \\
\hline \multicolumn{9}{|c|}{ Previous mental support from adult (other than guardian) } \\
\hline No & 1.00 & & 1.00 & & 1.00 & & 1.00 & \\
\hline Yes & 1.01 & $(0.34-3.03)$ & 1.88 & $(0.69-5.11)$ & 2.33 & $(1.17-4.63)$ & 2.00 & $(0.77-5.17)$ \\
\hline
\end{tabular}

a Separate models for each risk factor present.

b Other: student, housewife or pensioner.

c IES score $0-19$ as the reference category.

d Significant in the multivariate model with all risk factors analysed simultaneously.

Table 5

Logistic regression models of different risk factors for psychiatric disturbance (GHQ $\geq 9$ ) among exposed students and comparison students.

\begin{tabular}{|c|c|c|c|c|}
\hline \multirow[b]{2}{*}{ Risk factor $^{\mathrm{a}}$} & \multicolumn{2}{|c|}{ Exposed students } & \multicolumn{2}{|c|}{ Comparison students } \\
\hline & OR & $(95 \% \mathrm{CI})$ & OR & $(95 \% \mathrm{CI})$ \\
\hline \multicolumn{5}{|l|}{ Level of exposure } \\
\hline Mild to significant & 1.00 & & - & \\
\hline Severe or extreme & 2.57 & $(1.42-4.68)^{c}$ & - & \\
\hline \multicolumn{5}{|l|}{ Sex } \\
\hline Males & 1.00 & & 1.00 & \\
\hline Females & 3.95 & $(2.04-7.66)^{c}$ & 5.19 & $(2.50-10.77)^{\mathrm{C}}$ \\
\hline Age at the incident, years & 1.31 & $(1.11-1.55)^{c}$ & 1.04 & $(0.87-1.24)$ \\
\hline \multicolumn{5}{|l|}{ Socioeconomic status } \\
\hline Entrepreneur or upper middle class & 1.00 & & 1.00 & \\
\hline Lower middle class, working class or other ${ }^{\mathrm{b}}$ & 1.58 & $(0.88-2.86)$ & 1.79 & $(1.02-3.16)^{\mathrm{c}}$ \\
\hline \multicolumn{5}{|l|}{ Living arrangements } \\
\hline With both biological parents & 1.00 & & 1.00 & \\
\hline With one biological parent or otherwise & 1.99 & $(1.08-3.66)$ & 1.16 & $(0.63-2.14)$ \\
\hline \multicolumn{5}{|l|}{ Perceived social support } \\
\hline Family & 0.81 & $(0.73-0.90)^{c}$ & 0.82 & $(0.76-0.88)^{c}$ \\
\hline Friends & 0.97 & $(0.87-1.08)$ & 0.84 & $(0.78-0.90)^{c}$ \\
\hline \multicolumn{5}{|c|}{ Previous mental support from adult (other than guardian) } \\
\hline No & 1.00 & & 1.00 & \\
\hline Yes & 2.88 & $(1.22-6.78)$ & 6.33 & $(3.52-11.40)^{c}$ \\
\hline
\end{tabular}

a Separate models for each risk factor presented.

b Other: student, housewife or pensioner.

c Significant in the multivariate model with all risk factors analysed simultaneously.

\subsection{Risk factors for psychiatric disturbance}

Among exposed students, severe or extreme exposure against mild to significant exposure, female sex, older age at the incident, living with one biological parent and previous need for mental support increased the risk for psychiatric disturbance significantly (Table 5). Perceived social support from the family was found to be a significantly protective factor. In the multivariate model, the effects of the level of exposure, female sex, age at the incident and family support remained significant.

\section{Discussion}

Four months after the school shooting, posttraumatic distress was observed in almost half of the exposed students. The more serious the exposure, the higher the risk for posttraumatic stress 
and psychiatric disturbance was. Expectedly, the level of exposure had a significant effect on the severity of posttraumatic distress. Females were found to be more vulnerable than males. Perceived social support from the family was found to decrease the risk of distress after traumatisation significantly. The associations between psychological outcomes and risk and protective factors for posttraumatic and psychiatric disturbance appeared to be similar in the comparison group.

Our finding, that posttraumatic stress was strongly associated with the severity of exposure to the disaster and that females were especially vulnerable, is concurrent with previous findings $[5,11,42]$. Even though a significantly greater number of exposed females suffered from posttraumatic distress as compared to exposed males, exposed males were also found to suffer significantly more from posttraumatic distress and probable PTSD than males in comparison school.

Older children are suggested to become more affected by the trauma than younger children [5,39]. We found an association between older age, lack of perceived support from the family and sensitivity to psychiatric disturbance after traumatisation. The latter is consistent with previous findings indicating the importance of parental support $[13,16,33]$. However, unlike previous studies [32], we did not find a statistically significant correlation between low SES and a risk for posttraumatic distress. It is possible that the socioeconomic conditions are rather uniform within the Jokela community irrespective of occupation and therefore have little influence. Exposure to traumatic events increases risk for substance abuse $[3,6,10]$. In the present study, slight increase in substance use among exposed students compared to unexposed students was also found. In addition, community youth workers in Jokela have reported concern of alcohol use elsewhere [28]. The present analyses were based on $49 \%$ of the exposed students, which limits the representativeness of our results $[2,12,15]$. A longer follow-up and more thorough assessment using interviews of the subjects are needed for more specific evaluation of the consequences of trauma. Our present results may be an underestimate since students with most severe symptoms may have refused to participate. The students of Jokela High School were also irritated by the wide media attention and this may have reflected on the willingness to participate in the study.

The questionnaire including IES and GHQ are self-report screening scales, and therefore cannot be used as diagnostic instruments. However, they are predictive and valid in distinguishing the adolescents for high risk of posttraumatic stress and psychiatric disturbance or caseness $[1,23]$. By using dual cut-off scores in IES we aimed to identify those with posttraumatic distress compared to resilient individuals (19/20) and those with PTSD level of symptoms (34/35). The level of trauma exposure was measured by a scale created for this study assessing seriousness of the trauma exposure by six categories. Unfortunately, the scale does not differentiate between trauma types; life danger and personal loss. Further, it does not take into account the appraisal of the threat experienced at the exposure per se, which would be appropriate when evaluating the trauma symptoms occurring later [37]. We were not able to find applicable scale from the previous literature of considerate length especially paying regard to the experienced threat to life and losses suffered after such traumatisation. However, the severity of exposure assessed by this scale associated with symptom severity with an increasing effect (Table 2), which suggests the scale having a predictive value.

\section{Conclusion}

Follow-up of the students will be needed to evaluate factors accounting for the vulnerability or tolerability to trauma. Factors predicting good recovery and enduring or chronic posttraumatic reactions and comorbid psychiatric disorders need to be defined. Beyond symptom level, the ability to function and factors that influence the quality of life need to be investigated. Implication for crisis interventions would be enhancing connectedness among family and friends.

\section{Acknowledgements}

We thank the members of our research group for assistance and valuable comments. We also warmly thank the students and personnel of the Jokela and Pirkkala High Schools. The study was supported by Ministry of Social Affairs and Health, Finland, Finnish Medical Foundation and Rauha and Jalmari Ahokas Foundation.

\section{References}

[1] Aalto-Setälä T, Marttunen M, Tuulio-Henriksson A, Poikolainen K, Lönnqvist J Depressive symptoms in adolescence as predictors of early adulthood depressive disorders and maladjustment. Am J Psychiatry 2002;159:1235-7.

[2] Becker DF, Daley M, Gadbaille WJ, Green MR, Flaherty LT, Harper G, et al. Trauma and adolescence I: the nature and scope of trauma. In: Flaherty LT (chair). Committee on adolescence of the Group for the Advancement of Psychiatry. Adolescent psychiatry: developmental and clinical studies. New York, NY: The Analytic Press/Taylor \& Francis Group; 2003. p. 143-63.

[3] Becker DF, Grilo CM. Prediction of drug and alcohol abuse in hospitalized adolescents: comparisons by gender and substance type. Behav Res Ther 2006; $44: 1431-40$.

[4] Blumenthal JA, Burg MM, Barefoot J, Williams RB, Haney T, Zimet G. Social support, type A behavior, and coronary artery disease. Psychosom Med 1987;49:331-40.

[5] Bolton D, O'Ryan D, Udwin O, Boyle S, Yule W. The long-term psychological effects of a disaster experienced in adolescence: II: general psychopathology. J Child Psychol Psychiatry 2000;41:513-23.

[6] Breslau N, Davis GC, Schultz LR. Posttraumatic stress disorder and the incidence of nicotine, alcohol, and other drug disorders in persons who have experienced trauma. Arch Gen Psychiatry 2003;60:289-94.

[7] Broberg AG, Dyregrov A, Lilled L. The Goteborg discotheque fire: posttraumatic stress, and school adjustment as reported by the primary victims 18 months later. J Child Psychol Psychiatry 2005;46:1279-86.

[8] Copeland WE, Keeler G, Angold A, Costello EJ. Traumatic events and posttraumatic stress in childhood. Arch Gen Psychiatry 2007;64:577-84.

[9] Curle CE, Williams C. Post-traumatic stress reactions in children: gender differences in the incidence of trauma reactions at two years and examination of factors influencing adjustment. Br J Clin Psychol 1996;35(Pt 2):297-309.

[10] Danielson CK, Amstadter AB, Dangelmaier RE, Resnick HS, Saunders BE, Kilpatrick DG. Trauma-related risk factors for substance abuse among male versus female young adults. Addict Behav 2009;34:395-9.

[11] Dyregrov A, Frykholm AM, Lilled L, Broberg AG, Holmberg I. The Goteborg discotheque fire, 1998. Scand J Psychol 2003;44:449-57.

[12] Fletcher KE. Childhood posttraumatic stress disorder. In: Mash EJ, Barkley RA, editors. Child psychopathology. 2nd ed., New York, NY: Guilford Press; 2003. p. 330-71.

[13] Fremont WP. Childhood reactions to terrorism-induced trauma: a review of the past 10 years. J Am Acad Child Adolesc Psychiatry 2004;43:381-92.

[14] Fröjd SA, Nissinen ES, Pelkonen MU, Marttunen MJ, Koivisto AM, KaltialaHeino R. Depression and school performance in middle adolescent boys and girls. J Adolesc 2008;31:485-98.

[15] Giaconia RM, Reinherz HZ, Silverman AB, Pakiz B, Frost AK, Cohen E. Traumas and posttraumatic stress disorder in a community population of older adolescents. J Am Acad Child Adolesc Psychiatry 1995;34:1369-80.

[16] Gil-Rivas V, Silver RC, Holman EA, McIntosh DN, Poulin M. Parental response and adolescent adjustment to the September 11, 2001 terrorist attacks. J Trauma Stress 2007;20:1063-8.

[17] Goenjian AK, Pynoos RS, Steinberg AM, Najarian LM. Psychiatric comorbidity in children after the 1988 earthquake in Armenia. J Am Acad Child Adolesc Psychiatry 1995;34:1174-84.

[18] Goldberg DP. The detection of psychiatric illness by questionnaire; a technique for the identification and assessment of non-psychotic psychiatric illness. Maudsley monographs, vol. 21. London/New York: Oxford University Press; 1972.

[19] Holi MM, Marttunen M, Aalberg V. Comparison of the GHQ-36, the GHQ-12 and the SCL-90 as psychiatric screening instruments in the Finnish population. Nord J Psychiatry 2003;57:233-8.

[20] Horowitz MJ. Stress response syndromes and their treatment. In: Goldberger L, Breznitz S, editors. Handbook of stress: theoretical and clinical aspects. New York: Free Press; 1982. p. 711-32.

[21] Horowitz MJ, Wilner N, Alvarez W. Impact of Event Scale: a measure of subjective stress. Psychosom Med 1979;41:209-18.

[22] Hoven CW, Duarte CS, Lucas CP, Wu P, Mandell DJ, Goodwin RD, et al Psychopathology among New York city public school children 6 months after September 11. Arch Gen Psychiatry 2005;62:545-52. 
[23] Joseph S, Mynard H, Mayall M. Life-events and post-traumatic stress in a sample of English adolescents. J Community Appl Soc Psychol 2000;10:47582.

[24] Karlsson L, Kiviruusu O, Miettunen J, Heila H, Holi M, Ruuttu T, et al. One-year course and predictors of outcome of adolescent depression: a case-control study in Finland. J Clin Psychiatry 2008;69:844-53.

[25] Leskela US, Melartin TK, Lestela-Mielonen PS, Rytsala HJ, Sokero TP, Heikkinen $\mathrm{ME}$, et al. Life events, social support, and onset of major depressive episode in Finnish patients. J Nerv Ment Dis 2004;192:373-81.

[26] Littleton H, Grills-Taquechel A, Axsom D. Resource loss as a predictor of posttrauma symptoms among college women following the mass shooting at Virginia Tech. Violence Vict 2009;24:669-86.

[27] Lonigan CJ, Shannon MP, Finch AJ, Daugherty TK. Children's reactions to a natural disaster: symptom severity and degree of exposure. Adv Behav Res Ther 1991; $13: 135-54$.

[28] Ministry of Justice, Finland. Jokela School Shooting on 7 November 2007 Report of the Investigation Commission. Ministry of Justice Publications 2009:2. URL: http://www.om.fi/en/Etusivu/Julkaisut/1238674756100 [accessed June 23, 2010].

[29] Nader K, Pynoos R, Fairbanks L, Frederick C. Children's PTSD reactions one year after a sniper attack at their school. Am J Psychiatry 1990;147:1526-30.

[30] Neal LA, Busuttil W, Rollins J, Herepath R. Convergent validity of measures of post-traumatic stress disorder in a mixed military and civilian population. J Trauma Stress 1994;7:447-55.

[31] Palmer SC, Kagee A, Coyne JC, DeMichele A. Experience of trauma, distress, and posttraumatic stress among breast cancer patients. Psychosom Med 2004;66:258-64.

[32] Pine DS, Cohen JA. Trauma in children and adolescents: risk and treatment of psychiatric sequelae. Biol Psych 2002;51:519-31.
[33] Prinstein MJ, La Greca AM, Vernberg EM, Silverman WK. Children's coping assistance: how parents, teachers, and friends help children cope after a natural disaster. J Clin Child Psychol 1996;25:463-75.

[34] Pynoos RS, Frederick C, Nader K, Arroyo W, Steinberg A, Eth S, et al. Life threat and posttraumatic stress in school-age children. Arch Gen Psychiatry 1987;44:1057-63.

[35] Reijneveld SA, Crone MR, Verhulst FC, Verloove-Vanhorick SP. The effect of a severe disaster on the mental health of adolescents: a controlled study. Lancet 2003;362:691-6.

[36] Räikkönen K, Keskivaara P, Keltikangas-Järvinen L. Hostility and social support among Type A individuals. Psychol Health 1992;7:289-99.

[37] Schwarz ED, Kowalski JM. Malignant memories: PTSD in children and adults after a school shooting. J Am Acad Child Adolesc Psychiatry 1991;30:936-44.

[38] Shapiro F. EMDR: level 1 training manual. Pacific Grove, CA: EMDR Institute; 1996.

[39] Shaw JA. Children, adolescents and trauma. Psychiatr Q 2000;71:227-43.

[40] SPSS Base 16.0 Users Guide. Chicago, IL: SPSS Inc.; 2007.

[41] Tuisku V, Pelkonen M, Kiviruusu O, Karlsson L, Ruuttu T, Marttunen M. Factors associated with deliberate self-harm behaviour among depressed adolescent outpatients. J Adolesc 2009;32:1125-36.

[42] Udwin O, Boyle S, Yule W, Bolton D, O'Ryan D. Risk factors for long-term psychological effects of a disaster experienced in adolescence: predictors of Post-Traumatic Stress Disorder. J Child Psychol Psychiatry 2000;41:969-79.

[43] Ursano RJ, Fullerton CS, Kao TC, Bhartiya VR. Longitudinal assessment of posttraumatic stress disorders and depression after exposure to traumatic death. J Nerv Ment Dis 1995;183:36-42.

[44] Yule W, Bolton D, Udwin O, Boyle S, O'Ryan D, Nurrish J. The long-term psychological effects of a disaster experienced in adolescence: I: the incidence and course of PTSD. J Child Psychol Psychiatry 2000;41:503-11. 